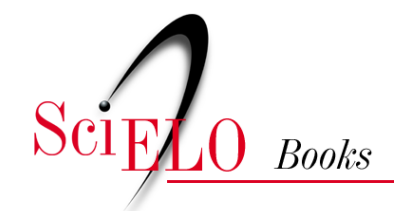

EDUFU

\title{
Elementos do trágico no estudo do texto teatral
}

\author{
Luiz Humberto Martins Arantes
}

SciELO Books / SciELO Livros / SciELO Libros

ARANTES, L.H.M. Elementos do trágico no estudo do texto teatral. In: FLORENTINO, A., and TELLES, N., eds. Cartografias do ensino do teatro [online]. Uberlândia: EDUFU, 2008, pp. 165-172. ISBN 978-85-7078-518-3. https://doi.org/10.7476/9788570785183.0017.

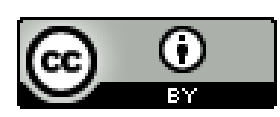

All the contents of this work, except where otherwise noted, is licensed under a Creative Commons Attribution 4.0 International license.

Todo o conteúdo deste trabalho, exceto quando houver ressalva, é publicado sob a licença Creative Commons Atribição $\underline{4.0}$.

Todo el contenido de esta obra, excepto donde se indique lo contrario, está bajo licencia de la licencia $\underline{\text { Creative Commons }}$ Reconocimento 4.0. 


\section{ELEMENTOS DO TRÁGICO NO ESTUDO DO TEXTO TEATRAL}

Escrever é uma certa maneira de desejar a liberdade; tendo começado de bom grado ou à força, você estará engajado ${ }^{1}$.

Se alguém me pedisse para dizer a principal crença da juventude de minha geração, eu diria sem titubear: a atribuição à arte de uma função transformadora da sociedade ${ }^{2}$.

Por uma questão de tempo e espaço, as metodologias de pesquisa e estudo do texto de teatro existentes não poderiam ser resumidas neste artigo, tamanha a quantidade e complexidade das mesmas ao longo de mais de dois mil anos de cultura teatral e criação literária ${ }^{3}$. Isto, considerando a tradição ocidental, que tem como marco a Poética aristotélica ${ }^{4}$.

No decorrer destes quase dois milênios e meio se alternaram, e se conjugaram, análises que privilegiaram ora a abordagem estrutural ora a perspectiva temática, coincidindo momentos em que ambas tinham importância aos olhos dos estudiosos. Assim, pode-se entender que a primeira foca estudos em torno da personagem, dos diálogos, do enredo, enfim, dos procedimentos que fazem funcionar a textualidade; enquanto a segunda procura olhar os elementos psicológicos, históricos e sociológicos que regulam o funcionamento da narrativa teatral, permitindo que a mesma libere as marcas de um tempo, o tempo que a tornou possível.

Pensando assim, o inglês Raymond Willians é um dos estudiosos da literatura e do texto teatral que mais se destacou no decorrer do século XX, fez amplo uso de análises que combinaram a análise do texto na sua relação com o contexto e vice-

${ }^{1}$ SARTRE, Jean-Paul. Que é a literatura? Tradução de Carlos Felipe Moisés. São Paulo: Ática, 1989. p. 53.

2 MACIEL, Luiz Carlos. Geração em transe: memórias do tropicalismo. Rio de Janeiro: Nova Fronteira, 1996. p. 73.

${ }^{3}$ Contribuíram para este artigo os processos e resultados adquiridos com o trabalho de pesquisa e ensino no Curso de Teatro na Universidade Federal de Uberlândia, ao qual estão vinculados os projetos de Pesquisa: Estudos do Texto Teatral: história, criação e temas e Biblioteca Digital de Peças Teatrais, ambos realizados com apoio e financiamento institucional da Universidade Federal de Uberlândia (UFU) e da Fundação de Amparo à Pesquisa do Estado de Minas Gerais (Fapemig).

${ }^{4}$ ARISTÓTELES. Arte poética. São Paulo: M. Claret, 2003. p. 26. 
-versa, não deixando de ressaltar a importância da aproximação entre o literário e o performático, ou seja, as possibilidades de cena que são inerentes a todo texto teatral.

Em suas pesquisas a respeito de gêneros e história do texto teatral, Willians sempre se incomodou com certos determinismos literários, um exemplo foi o debate que travou com o crítico literário George Steiner a respeito da questão do trágico e sua historicidade, pois Steiner acreditava na "[...] impossibilidade da experiência trágica nos tempos modernos [...]. Acidentes de automóvel não podiam ser chamados de trágico"s.

Deste debate, surge a idéia de que não se deve negar a tragédia como tradição, mas que se deve sim reconhecer a pertinência de se falar em 'elementos trágicos' presentes numa obra literária, teatral e até mesmo nas nossas experiências contemporâneas. Mas, para isso, acreditou ser necessário enfrentar os princípios da teoria da tragédia, tais como ordem e acidente, a destruição do herói, a ação irreparável e a morte e a ênfase sobre o mal'.

Em recente entrevista jornalística, o crítico literário britânico Terry Eagleton, ao ser indagado se não estaríamos fadados a 'viver atualmente' uma tragédia grega, o Eagleton respondeu que sim, pois indícios e elementos trágicos estão muito presentes nos tempos atuais, principalmente quando se toca na questão dos recentes atos terroristas:

[...] Os mitos da Grécia Antiga contam histórias de limitações humanas, de barreiras que não podem ser ultrapassadas e sobre o alto preço que pagamos ao transgredir esses limites. Para o Ocidente, principalmente no tocante à cultura americana, o problema existe no desejo infinito. O Ocidente vive um mito faustiano de ganância perpétua, que nunca se contenta. E isso certamente nos levará à autodestruição ${ }^{7}$.

Pensando na atualização destes elementos trágicos no âmbito do literário/teatral e do real é que um importante dramaturgo brasileiro merece ser recuperado, pois também transitou pelas fronteiras dos gêneros, qual seja: o dramaturgo Jorge Andrade (1922-1984). É o que acontece ao se analisar textos como A Moratória (1954) e Rastro Atrás (1965), obras em que tenciona elementos formais como o drama e características do épico. Com perspectiva semelhante é o que o autor irá também realizar em Pedreira das Almas (1957), obra em que articula um enredo tecido a partir das proximidades e distanciamentos entre o drama e o trágico, ou melhor, elementos do trágico.

Os textos teatrais de Jorge Andrade foram escritos entre o início dos anos 1950 e meados da década de 1960. Dentre todas as características desse período, sempre se lembra a intensa democratização que marcou tal intervalo de tempo. Momento em que se debatiam os resultados do período Vargas, avaliava-se seu retorno ao poder e pesavam-se os impactos da abertura do país ao capital automobilístico estrangeiro. Também um período de expectativa com a prosperidade projetada pelo governo Kubitschek, assim como de endividamento, visando à realização de grandes projetos, como foi o caso da construção de Brasília.

\footnotetext{
${ }^{5}$ WILLIANS, Raymond. Tragédia moderna. São Paulo: Cosac \& Naify, 2002. p. 14.

6 WILLIANS, 2002, p. 70.

7 EAGLETON, Terry. Duelo de Titãs. Folha de S. Paulo, São Paulo, 04 jan. 2006. Caderno Mais!, p. 4.
} 
Ao lado disso, também foi um período em que se "respirou aliviado", com a saída de um momento marcado por guerras e ditaduras. Numa conjuntura mais ampla, pensando a América Latina em sua totalidade, a tensão acerca da ocupação do poder estava solta, haja vista que a Guerra Fria entre capitalistas e comunistas informava o debate ao sul do Equador.

Diante de tudo isso, algo pareceu evidente no debate público, a discussão em torno do tema da liberdade. Fora debatido em suas várias nuances: negação da ditadura anterior, liberdade para construir a nacionalidade e liberdade para evitar outras experiências ditatoriais.

É possível perceber que o debate sobre a questão da liberdade perpassou a aparente conotação política, alcançando também o meio artístico e estético dos anos 1950 e 1960. Para restringir-se apenas ao meio teatral, basta lembrar a evidência que o tema recebeu com o Teatro de Arena, o Teatro Oficina e o Teatro Opinião, especificamente, com a crescente pressão das forças conservadoras para a efetivação do golpe de 1964.

$\mathrm{O}$ dramaturgo Jorge Andrade viveu esse contexto em toda a sua intensidade. Estudou e formou-se em teatro, dialogou com referências teatrais e historiográficas do momento e, com a publicação e encenação de suas peças, procurou interferir no debate público que então se realizava em torno da questão da liberdade, fosse respirando democracia fosse receando a proximidade do golpe militar.

Diante da necessidade de enfrentar presente, Jorge Andrade não escreveu apenas uma peça, pois a riqueza da temática e a urgência do momento levaram-no a tecer tramas e personagens que dialogavam com importantes bandeiras de luta política da década de 1960, o que pode ser observado em As Confrarias (1968), Pedreira das Almas (1957), A Escada (1960), Rastro Atrás (1966) e O Sumidouro (1967).

Se há um tema em Jorge Andrade no qual se vislumbra a presença de 'elementos trágicos' em sua obra, sem dúvida é a forma como ele processa a busca da liberdade e, principalmente, como o dramaturgo tece suas personagens diante desta clássica 'bandeira' de luta política.

Assim, pode-se perceber que o tema da liberdade em Jorge Andrade não é propriamente inaugurado na década de 1960, pois, já em 1957, o texto Pedreira das Almas apontava para a presença do tema em sua dramaturgia. Nesta peça, o dramaturgo articula uma tripla temporalidade, visto que é escrita no final de década de 1950, mas possui um enredo que remete à Revolta Liberal de 1842. No entanto, ela é publicada, ao lado do conjunto da obra, em 1970, quando o país atravessava os momentos mais truculentos da ditadura militar.

A busca da liberdade é sustentada por tensões que também aparecem em outras peças, tais como a relação passado/presente, tradicionais/progressistas, no conflito entre aqueles que desejam partir e aqueles que precisam ficar.

Diante dessa polarização, a personagem Urbana destaca-se, pois ela viu a vila de Pedreira surgir, crescer e, frente à sua decadência, não quer deixá-la. A sua verdade é permanecer junto aos mortos de seu passado. Ela é a continuidade de uma tradição construída na 'rocha':

Urbana: Encontraram sinais estranhos na rocha, e uma imagem de São Tomé no nicho de pedras. "Este é o lugar para a cidade. São Tomé nos protegerá, como nos protegeu da tormenta!” Descobriram ouro na gruta. Abriram galerias que foram sair 
em dez pontos diferentes do morro, como se fossem dez portas de Pedreira. Mais tarde, partindo daqui, abriram lavras por todo o vale e fundaram novos lugarejos ${ }^{8}$.

A firme opinião de Urbana irá contrastar com o espírito novidadeiro dos mais jovens, entre eles, aparece Gabriel, que vê na partida para outras terras o único caminho de busca da prosperidade. Para cumprir seu objetivo, Gabriel procura aliciar Mariana a Martiniano, ambos de filhos de Urbana.

Esse conflito, que tem como pano de fundo o embate político entre liberais e conservadores, em 1842, prevalece até a chegada, em Pedreira, de um batalhão de policiais comandados pelo delegado Vasconcelos, que traz, algemado, o ‘subversivo' Martiniano.

Logo na sua entrada à cidade, Vasconcelos propõe trocar a liberdade de Martiniano pela delação de Gabriel. Inconformado com a possibilidade da troca, Martiniano - mártir? - se solta dos soldados e sai correndo. Aos gritos, a mãe e toda a vila vêem o jovem cair fuzilado. Após a morte, um novo conflito se apresenta, pois já não há mais lugar no cemitério, ninguém pode sair da vila para buscar terra para se construir novos túmulos. Como desafio à autoridade e às atrocidades do poder de Vasconcelos, Mariana sugere que o corpo fique exposto como exemplo.

Mariana: Leis! Leis! Não aceitamos, nem o povo de Pedreira das Almas aceitará suas leis.

Vasconcelos: (Áspero) Falo com dona Urbana.

Mariana: Respondo por ela e por Pedreira. Todas as leis que o senhor representa, não nos poderão arrancar nenhuma palavra, nem um gesto de acatamento às suas ordens. Abra as suas portas das prisões, traga os instrumentos de tortura, revolva e destrua a cidade, derrube as torres de nossa igreja...! Mas de nossas bocas jamais sairá uma única palavra de delação Os mortos sairão das lajes e os impiedosos serão destruídos! (Os soldados entreolham-se, admirados) Que um anátema caia sobre suas cabeças! Que o corpo de meu irmão fique exposto... será uma lembrança viva do seu pecado, da sua indignidade!

Vasconcelos: Veremos mais tarde, minha senhora, se não falam.

Mariana: O senhor tem as espadas... nós, aquilo que assassinos de sua espécie desconhecem: respeito à liberdade. É o que Gabriel representa para nós. Pagaremos, por ele, qualquer preço9!

Mais uma vez, retorna a imagem do corpo que permanecerá insepulto, o que reforça novamente a tensão entre as leis naturais e as leis do Estado. Diante do fuzilamento do irmão e a iminente prisão do namorado, a jovem Mariana assume a defesa da liberdade, pois se, anteriormente, seu direito de ir e vir era ameaçado pela força da tradição da mãe, no momento seguinte, a situação transforma-se, já que a questão da busca da liberdade ganha uma conotação política.

Após a perda do irmão e a fuga do revolucionário Gabriel, coube a Mariana o enfrentamento da opressão, no caso, representado na figura do delegado Vasconcelos.

\footnotetext{
${ }^{8}$ ANDRADE, Jorge. Pedreira das almas. In: p. 81-82 . Marta, a árvore e o relógio. São Paulo: 1970.

9 ANDRADE, 1970, p. 97.
} 
Mariana: Entre na igreja, diante de seus soldados, e prove que suas leis não são ímpias. Onde está sua justiça para ajudá-lo a transpor esta porta? Onde o poder que o levará até aqueles corpos? Não passam de mortos, disse o senhor! Então, deve ter coragem para insultá-los com sua presença. [...] Se o senhor não suporta, por que suportarão eles? O senhor nos prometeu um túmulo, se revelássemos onde está Gabriel. Gabriel está lá, como minha mãe, caído sobre Martiniano. O senhor nos impôs, como condição da sua opressão, o corpo exposto de Martiniano. Nós só lhe impomos, para a nossa delação, a sua entrada na igreja. Entre e veja o que suas leis fizeram dos homens, depois de terem feito à província, empobrecendo a terra com seus tributos e toda sorte de impiedades ${ }^{10}$ !

As leis do Estado parecem chegar àquela localidade pelas vias da força e da imposição, o que justifica as reações de Mariana e das demais mulheres. Considerando que esse texto perpassou os anos 1960 e só veio a ser publicado em 1970, há que se observar que ele estabelece um íntimo diálogo com a idéia de engajamento do período. A narrativa aponta claramente para os poderes opressivos e até mesmo para os métodos de tortura exercidos pelo Estado ditatorial.

Vasconcelos: Será processada e responderá pelo crime de Gabriel.

Mariana: Já estou com as mãos amarradas. Faça cumprir suas leis! Martiniano também estava, como está o povo da Província desde os dias da Bela Cruz. Desde que nossa montanha passou de sesmaria de ouro a pedra para os mortos. Onde está Gabriel? Onde os mortos estão expostos, e os vivos presos nas rochas, sonham com uma terra mais justa. Gabriel é a única saída deste túmulo imenso que seu Governo fez de Pedreira das Almas. Faça cumprir suas leis, já que não pode fazer os mortos reviverem. Este é o nosso preço, senhor. $\mathrm{O}$ meu e o seu. $\mathrm{O}$ senhor não terá nunca Gabriel, porque matou Martiniano... e eu... porque deixei Martiniano e minha mãe morrerem! Chame seus soldados e entre na igreja! Prove a eles que não teme os mortos. Que pode encarar seus crimes. (Silêncio. Vasconcelos continua imóvel) Governos como o seu, senhor, só executam leis ímpias, mas com braços subordinados ou mãos escravas. Não presenciam nunca a verdadeira imagem de suas vítimas. Se o senhor entrar... (Vacila, fazendo um grande esforço)... naquele rosto desfigurado... que era a própria imagem do nosso sonho... verá a que ficou reduzida a Província sob sua justiça! Só aí poderá saber o que Gabriel representa para nós. Entre!... e Gabriel será seu! Eu também prometo ${ }^{11}$ !

Aceitando o desafio, o delegado resolve entrar na igreja, e o que o leitor percebe é a indicação do dramaturgo que descreve a expressão de horror que domina o rosto de Vasconcelos. O que ele teria visto? Os corpos amontoados? Desfigurados? As indicações do autor não são diretas, deixando no subtexto o que o delegado teria presenciado dentro da igreja. Com toda certeza, estavam lá os corpos de Martiniano e Urbana, mas o estado em que estavam não é descrito claramente, cabe ao leitor/ diretor/espectador a construção do sentido.

Sabe-se, ainda, que o acontecido foi o suficiente para os soldados fugirem e 
o delegado desistir de Gabriel. Em seguida, Mariana entra para a igreja e proíbe as outras mulheres de contarem a Gabriel os fatos ocorridos. Ninguém deve comentar ou lembrar a imagem que se viu de Martiniano.

Ao fim, a vila apresenta sinais de abandono, empoeirada e com papel sendo levado pelo vento aos quatro cantos. Mariana, cada vez mais parecida com a mãe, é observada por Padre Gonçalo, dando indícios de que não vai partir com o restante da vila, nem mesmo para acompanhar Gabriel.

O diálogo final é entre Gabriel e Mariana, também é a última tentativa de demovê-la da idéia fixa de não partir para outras terras.

Mariana: Mais forte do que as promessas é a morte que nos liga à terra. Sinto tudo dentro do meu corpo, como se fizesse parte do meu sangue. As rochas... a igreja... o adro!

Gabriel: Mariana! Não podemos passar a vida venerando mortos. Foi para escapar a isso que sonhamos partir. É preciso saber escolher, Mariana. (...)

Mariana: Gabriel! Duas pessoas perderam a vida. Não compreendes? Duas pessoas que eram a minha família. Como queres que seja a mesma?

Gabriel: Também perdi a minha.

Mariana: Há muito tempo. Viveste sem ela.

Gabriel: Prometeste uma para mim. Não te lembras.

Mariana: Não a este preço.

Gabriel: Mas que preço? Foi o próprio mundo de Pedreira que matou Martiniano, como matou minha família.

Mariana: Nossos mortos não podem ser abandonados ${ }^{12}$.

A jovem Mariana assume todo o apego da mãe à vila de Pedreira. Não bastando, quer também estar junto aos mortos. Tal como a mãe quer valorizar o passado em detrimento do presente, o qual é representado pelo personagem Gabriel. $\mathrm{Na}$ despedida do jovem casal, é marcante a emoção construída:

Gabriel: Pedreira! Vista de longe, perdida entre as nuvens, parece uma estrela branca de mármore! (consigo mesmo) O passado é um monstro... que nos acompanha para onde vamos ${ }^{13}$ !

A personagem Urbana simboliza uma tradição consolidada, que valoriza o passado e os mortos da vila. Diante da 'velha senhora', Gabriel precisa satisfazer às necessidades históricas do presente, por isso, precisa do rompimento, deseja partir para outras terras e construir o novo. No início, Mariana acredita na urgência da partida, mas, diante do passado, que pode ser esquecido, resolve ficar e defender o direito à lembrança. Ela será uma inventora de tradições, a sua atitude de ficar irá provocar uma nova coesão na coletividade, não a mesma da mãe, mas sim, novas definições de comunidade e de pertencimento a um grupo ${ }^{14}$.

${ }_{12}$ ANDRADE, 1970, p. 112.

13 ANDRADE, 1970, p. 114.

${ }_{14}$ PINTO, Júlio Pimentel. Uma memória do mundo: ficção, memória e história em Jorge Luis Borges. São Paulo: Estação da Liberdade, 1998. p. 57. 
Essa peça de Jorge Andrade traz a defesa da liberdade, mas como uma bandeira daqueles que acreditam que as mudanças são possíveis, mesmo sacrificando vidas. Martiniano pagou este preço. Gabriel partiu para construir o novo, e Mariana articulou a novidade e o arcaico, o passado e o presente, rebelou-se contra as leis artificiais do Estado, entretanto, ao fim, apostou na conservação da tradição deixada pela mãe e seus antepassados.

Esses três personagens de Pedreira das Almas, mais uma vez, reforçam a idéia de que Jorge Andrade construía seus textos com os olhos no passado, mas com os pés no presente. Por ser escrita em 1957 e divulgada neste contexto auxiliou o dramaturgo a participar do debate do momento, qual seja: o processo de construção do 'homem novo'15.

A partir da década de 1950, vários setores da sociedade brasileira passaram a refletir a construção desse novo homem. Havia, assim, uma valorização da vontade de transformação, da ação humana capaz de mudar o curso da história. As raízes deste homem brasileiro deviam, portanto, ser buscadas no passado, no 'autêntico homem do povo', ainda com características rurais e sem a contaminação da urbanidade capitalista $^{16}$.

Pensando assim, Jorge Andrade aproxima-se das influências de esquerda, dos comunistas ou trabalhistas do final da década de 1950. Mas esta aproximação temática não é tranqüila no universo ficcional. Se as idéias da 'utopia revolucionária' propunham a ruptura, Jorge Andrade diferencia-se e lança um olhar singular sobre esse homem novo.

O dramaturgo mostra a coragem de Gabriel para romper com a tradição de Urbana. Mas, ao mesmo tempo, apresenta as agruras de Mariana com uma consciência que se divide entre o ficar e o partir. Se o dramaturgo ressalta a força do rompimento, não deixa de ser verdade que este se realizou com perdas, pois Gabriel teve de partir sem a noiva Mariana.

Se o homem novo das 'utopias revolucionárias' é decidido e está pronto para, se necessário, pegar em armas, o de Jorge Andrade titubeia entre passado e presente, ao duvidar da tradição e não vislumbrar que o novo que se aproxima deixa florescer toda sua humanidade, o que o faz pensar e pesar as perdas de suas decisões.

Por fim, a imagem do corpo insepulto em praça pública, tecida por Jorge Andrade, não caracteriza o texto como tragédia, tal como ocorre em Antígona de Sófocles, mas é uma intertextualidade que aponta para o que Raymond Willians descreve como a presença de 'elementos trágicos' nos textos da modernidade.

15 O final da década de 1950 reforçou, no campo das esquerdas, a procura deste homem novo, aquele "[...] a que se referia o jovem Marx, termo recuperado com entusiasmo na época pela revolução cubana - e pelos escritos daquele que é chamado romanticamente em Cuba de 'guerrilheiro heróico', Che Guevara”. RIDENTI, Marcelo. Em busca do povo brasileiro: artistas da revolução, do CPC à era da TV. São Paulo: Record, 2000. p. 120.

${ }^{16}$ RIDENTI, 2000, p. 24. 


\section{REFERÊNCIAS}

ANDRADE, Jorge. Pedreira das almas. In: . Marta, a árvore e o relógio. São Paulo:

Perspectiva, 1970. p. 71-116.

ARANTES, Luiz Humberto M. Do passado ao presente: história, textos e cenas na dramaturgia de Jorge Andrade. 223 p. Tese (Doutorado) - Pontifícia Universidade Católica de São Paulo, São Paulo, 2003.

ARANTES, Luiz Humberto M. Teatro da memória: história e ficção na dramaturgia de Jorge Andrade. São Paulo: Annablume: Fapesp, 2001.

ARISTÓTELES. Arte poética. São Paulo: M. Claret, 2003.

EAGLETON, Terry. Duelo de Titãs. Folha de S. Paulo, São Paulo, 04 jan. 2006. Caderno Mais!, p. 4-5.

MACIEL, Luiz Carlos. Geração em transe: memórias do tropicalismo. Rio de Janeiro: Nova Fronteira, 1996.

PINTO, Júlio Pimentel. Uma memória do mundo: ficção, memória e história em Jorge Luis Borges. São Paulo: Estação da Liberdade, 1998.

RIDENTI, Marcelo. Em busca do povo brasileiro: artistas da revolução, do CPC à era da TV. São Paulo: Record, 2000.

SARTRE, Jean-Paul. Que é a literatura? Tradução de Carlos Felipe Moisés. São Paulo: Ática, 1989.

WILLIANS, Raymond. Tragédia moderna. São Paulo: Cosac \& Naify, 2002. 